\title{
The Association of ADHD and Depression: Mediation by Peer Problems and Parent-Child Difficulties in Two Complementary Samples
}

\author{
Kathryn L. Humphreys, Shaina J. Katz, \\ Steve S. Lee, and Constance Hammen \\ University of California, Los Angeles
}

\author{
Patricia A. Brennan \\ Emory University
}

Jake M. Najman

University of Queensland

\begin{abstract}
Children with attention-deficit/hyperactivity disorder (ADHD) are at increased risk for the development of depression, with evidence that peer and academic difficulties mediate predictions of later depression from ADHD. In the present study, we hypothesized that parent-child relationship difficulties may be an additional potential mediator of this association. Academic, peer, and parent-child functioning were tested as mediators of the association of attention problems and depression in two distinctly different yet complementary samples. Study 1 was a cross-sectional sample of 5 - to 10 -year-old children $(N=230)$ with and without ADHD. Study 2 was a prospective longitudinal sample of 472 youth, followed prospectively from birth to age 20 years, at risk for depression. Despite differences in age, measures, and designs, both studies implicated peer and parent-child problems as unique mediators of depressive symptoms, whereas academic difficulties did not uniquely mediate the ADHD-depression association. Furthermore, inattention symptoms, but not hyperactivity, predicted depressive symptoms via the disruption of interpersonal functioning. The inclusion of oppositional defiant disorder into models impacted results and supported its independent role in parent-child problems. Implications include support for interventions that target interpersonal competence, which may effectively reduce the risk of depression among children with ADHD.
\end{abstract}

Keywords: ADHD, depression, peer problems, peer rejection, parent-child relationship

The association between attention-deficit/hyperactivity disorder (ADHD) and depression has been well documented across epidemiological and clinical samples of children and adolescents (e.g., Anderson, Williams, McGee, \& Silva, 1987; Biederman et al., 2008; Biederman, Newcorn, \& Sprich, 1991). Given that ADHD typically precedes the onset of depression (American Psychiatric Association, 2000), studies of the association of ADHD and depression have focused on ADHD-related impairments or failurerelated mediators (i.e., academic and peer failure), such that depression may follow from ADHD-related demoralization (Biederman, Mick, \& Faraone, 1998). The dual-failure model proposes that both academic and peer problems, resulting from disruptive behavior problems, contribute to the development of depression (e.g., Patterson \& Stoolmiller, 1991). Similar to the dual-failure model, Cole's (1990) competency-based model asserts

Kathryn L. Humphreys, Shaina J. Katz, Steve S. Lee, and Constance Hammen, Department of Psychology, University of California, Los Angeles; Patricia A. Brennan, Department of Psychology, Emory University; Jake M. Najman, School of Population Health, University of Queensland, Brisbane, Queensland, Australia.

Kathryn L. Humphreys and Shaina J. Katz contributed equally and share first authorship, listed alphabetically.

Correspondence concerning this article should be addressed to Department of Psychology, University of California, Los Angeles, Box 951563, Los Angeles, CA 90095-1563. E-mail: sjkatz@ucla.edu that negative feedback obtained from failure is a pathway to depression.

Children with ADHD typically fare worse academically and socially than their non-ADHD counterparts (e.g., Hoza, Waschbusch, Owens, Pelham, \& Kipp, 2001), and attention problems typically precede academic problems (e.g., Smart, Sanson, \& Prior, 1996). Herman, Lambert, Ialongo, and Ostrander (2007) found that academic problems mediated the association of attention problems with depression measured two years later, even after controlling for baseline conduct problems and academic performance. Peer relationships are also reliably disrupted in children with ADHD (Henker \& Whalen, 1999), and approximately half of children from the Multimodal Treatment Study of Children With ADHD were sociometrically rejected (Hoza et al., 2005). Both academic and peer impairment are known to predict depressive symptoms (e.g., McCarty et al., 2008; Seroczynski, Cole, \& Maxwell, 1997). In children ages 6-9 years, others' appraisals of social competence were found to mediate the association of ADHD and depression (Ostrander, Crystal, \& August, 2006).

Interpersonal difficulties, defined broadly, are associated with risk for depression across development (e.g., Rudolph et al., 2000). Thus, in addition to peer relationships, the parent-child relationship may be relevant to depression risk in children with ADHD. The majority of extant research on parent-child relationships and child outcomes has focused primarily on its association with ADHD symptoms rather than the development of psychopathology 
in other domains. In one notable exception, Ostrander and Herman (2006) found that parent management, a measure of parenting behavior, fully explained the association between ADHD and depression in young children, but not in older children.

Families of children with ADHD are characterized by poor parent-child relationships, including greater conflict, problematic child behavior, and poorer parenting practices (Barkley, Fischer, Edelbrock, \& Smallish, 1991; Johnston \& Mash, 2001). Children with ADHD are also thought to require greater parental effort than those without ADHD (Barkley, Anastopoulos, Guevremont, \& Fletcher, 1992), which may disrupt normative parenting behavior (Anastopoulos, Shelton, DuPaul, \& Guevremont, 1993). Longitudinal evidence suggests that child ADHD may precede both parent-child rejection and hostility (Lifford, Harold, \& Thapar, 2008, 2009), and problematic parent-child interactions, specifically, have uniquely predicted depression and antisocial behavior (Eberhart \& Hammen, 2006; Patterson, DeBaryshe, \& Ramsey, 1989). There is also evidence that parent-child problems increase the risk for depression among children with ADHD (Johnston \& Mash, 2001; Ostrander \& Herman, 2006).

Because ADHD is associated with multiple domains of impairment, multiple potential mediators must be evaluated simultaneously. In particular, the parent-child relationship has been largely omitted in understanding the progression from ADHD to depression. Accordingly, the present investigation addressed these concerns directly by examining the role of three potential mediators in the association between ADHD and depression. Specifically, we used structural equation modeling (SEM) to examine whether ADHD symptoms predicted academic problems, peer problems, and parent-child problems, and whether these three facets further predicted individual differences in depressive symptoms. To our knowledge, this is the first study to use SEM and multiple mediation to examine the independent effect of each mediator. In addition, to more clearly examine the independent role of attention problems over and above oppositional defiant disorder (ODD), secondary models included both ADHD and ODD/aggression factors, given their frequent overlap (Biederman et al., 1991) and the association of ODD with poorer interpersonal functioning and increased depression risk (Capaldi, 1991; Panak \& Garber, 1992).

Study 1 consisted of a cross-sectional sample of children ages 5-10 years, oversampled for children who met full diagnostic criteria for ADHD. This sample yielded multimethod measures of ADHD symptom dimensions that permitted separate examination of the role of inattention versus hyperactivity in their association with depressive symptoms. Previous studies of ADHD and depression have typically ignored this distinction, even when examined dimensionally (e.g., Seymour et al., 2012). This may mask important differences in symptom domains (e.g., inattention was a better predictor of internalizing problems than hyperactivity; Willcutt et al., 2012). Study 2 is a prospective longitudinal study of the offspring of depressed and never-depressed mothers, and thus constitutes an enriched sample of individuals at high risk for depression. This large sample allowed testing of whether childhood attention problems conferred risk for interpersonal difficulties in adolescence and, in turn, depression in the transition to adulthood. These time points are significant developmentally as adolescent interpersonal difficulties are known predictors of psychosocial problems (e.g., poorer romantic relationship quality; Katz, Hammen, \& Brennan, 2013) and psychopathology (e.g., depression; Eberhart \& Hammen, 2006). Furthermore, age 20 was an appropriate age for assessing depression as the 20 s are a common age range for initial onset of major depression (Kessler et al., 2010). In addition, given the known sex differences in ADHD prevalence (Szatmari, Offord, \& Boyle, 1989), as well as sex differences in depression prevalence (Piccinelli \& Wilkinson, 2000), we included sex as both a covariate in our analyses and a moderator of associations in our final models.

\section{Study 1}

\section{Method}

Participants. Recruitment and procedures for this sample have been described previously (Humphreys, Mehta, \& Lee, 2012; Shemmassian \& Lee, 2012). In brief, 230 children with $(n=120)$ and without $(n=110)$ ADHD, ages $5-10$ years $(M=7.39$ years, $S D=1.12), 71 \%$ male, and their families were recruited. Fortyseven percent of the sample was Caucasian, 8\% African American, 9\% Hispanic, $3 \%$ Asian, $21 \%$ mixed, and $12 \%$ as other or missing. All study procedures were approved by the University of California, Los Angeles Institutional Review Board.

Measures.

Diagnostic Interview Schedule for Children (4th ed.; DISCIV; Shaffer, Fisher, Lucas, Dulcan, \& Schwab-Stone, 2000). We administered the computerized DISC-IV to each parent. We separately analyzed the 18 Diagnostic and Statistical Manual for Mental Disorders (4th ed.; DSM-IV) ADHD symptoms (nine inattention and nine hyperactivity). Test-retest reliability for ADHD from the DISC-IV ranged from .51 to .64 in the DSM-IV field trials (Lahey, Applegate, McBurnett, \& Biederman, 1994), and there is strong evidence for the predictive validity and sensitivity to treatment effects of the DISC-IV (Pelham, Fabiano, \& Massetti, 2005). The DISC-IV also provided the number of ODD symptoms endorsed $(0-8)$.

Disruptive Behavior Disorder Rating Scale (DBD; Pelham, Gnagy, Greenslade, \& Milich, 1992). Parents rated DSM-IV DBD symptoms with response options ranging from $0=$ not at all to 3 = very much. The 18 symptoms that compose DSM-IV ADHD were summed to create dimensional measures of inattention and hyperactivity symptoms, which were split into odd- and even-item scales. The eight ODD symptoms were also obtained via the DBD rating scale and split into odd- and even-item scales. Evidence of validity of the DBD has been shown in previous studies of school-age children with ADHD (Owens \& Hoza, 2003).

Child Behavior Checklist 6-18 (CBCL; Achenbach \& Rescorla, 2001). The 113-item rating scale completed by the parent yielded measures of child psychopathology. Responses were scored on a 3 -point scale, from $0=$ not true to $2=$ very true or often true. The CBCL was normed on a large sample of children ages 6-18 years and possesses excellent test-retest and interrater reliability, as well as adequate to excellent internal consistency (Achenbach \& Rescorla, 2001). We used the total score from the Withdrawn/Depressed narrow-band subscale as our measure of depression. This subscale has been shown to have adequate internal consistency and test-retest reliability (Achenbach \& Rescorla, 2001) and discriminated youths with major depressive disorder or 
dysthymia from youths without these diagnoses (Ebesutani et al., 2010).

Wechsler Individual Achievement Test-Second Edition (Wechsler, 2002). The Word Reading and Math Reasoning subtests of the Wechsler Individual Achievement Test-Second Edition were used to estimate academic achievement. The Word Reading subtest assesses phonemic awareness and reading fluency, and the Math Reasoning subtest assesses computational knowledge and the calculation of word problems. Standard scores for both subtests were $z$-scored and summed to create a composite measure of academic achievement.

Dishion Social Preference Scale (Dishion, 1990). This is a three-item (5-point metric) parent-completed measure of peer acceptance, rejection, and being ignored. We estimated negative social preference, our measure of peer problems, by subtracting the rejection rating from the acceptance rating, which is consistent with prior work (Lee \& Hinshaw, 2006; Shemmassian \& Lee, 2012).

Parenting Stress Index: Short Form (Abidin, 1995). The Parent-Child Dysfunctional Interaction subscale assesses parental perception that the child does not meet expectations and that interactions with the child are not reinforcing. This subscale consists of 12 items rated from $1=$ strongly disagree to $5=$ strongly agree. Higher scores indicate more parent-child dysfunction. Psychometric properties for the Parenting Stress Index: Short From have been previously shown to be adequate (Abidin, 1995).

Data analytic procedures. Initial data compilation and analysis were completed using PASW (Version 18.0) software. Our general data analytic approach consisted of SEM to assess associations among constructs that are corrected for biases attributable to random error and construct-irrelevant variance (Bollen, 1989) on standardized variables. We used SEM to simultaneously compare the unique contribution of peer problems, academic achievement, and parent-child problems as mediators of the association of ADHD and depression. Given the substantial variability in scales of the observed variables, these were converted to $z$-scores prior to conducting analyses to facilitate the interpretability of results. To account for nonnormality in multiple variables, we used robust maximum likelihood procedures in Mplus (Muthén \& Muthén, 1998-2010) to obtain model estimates.

Goodness of fit of the initial and alternative models was assessed with the maximum-likelihood chi-square statistic, the comparative fit index (CFI), the standardized root mean square residual (SRMR), and the root mean square error of approximation (RMSEA). The CFI ranges from 0.00 to 1.00 and reflects the improvement in fit of a hypothesized model over a model of complete independence among the measured variables. Values approaching 0.95 or greater are desirable for the CFI. The RMSEA is a measure of fit per degrees of freedom, controlling for sample size. Values of .06 or less for RMSEA and values of .08 for SRMR indicate a relatively good fit ( $\mathrm{Hu} \&$ Bentler, 1999).

To interrogate the potential separate effects of ADHD symptoms, we created latent variables for inattention and hyperactivity. To provide a sufficient number of independent indicators for each latent variable, we divided the two DBD symptom dimension scores into odd-item and even-item composites (Kelloway, 1998). These separate indicators, along with the number of inattention and hyperactivity symptoms from the DISC-IV, composed the three indicators for each inattention and hyperactivity latent factor. The same procedure was used to create an ODD latent factor.

\section{Results}

Descriptive statistics and bivariate correlations among ADHD, ODD, mediator, and depression variables are presented in Table 1. Significant positive associations were observed among all measures of ADHD. In addition, all ADHD variables showed significant positive associations with peer problems and parent-child problems, whereas four of the six ADHD variables were associated with (poorer) academic achievement. Peer problems and parentchild problems were both significantly associated with depression, whereas academic achievement was not. Five of the six ADHD variables were significantly associated with depression.

Proposed structural model. Covariates in the model included participant sex and age. To examine the indirect effect of inattention and hyperactivity symptom dimensions on depression via multiple mediators, we regressed depression on peer problems, academic achievement, and parent-child problems, which were in turn regressed on the two latent ADHD symptom dimensions, set to covary. This initial model had suboptimal fit, $\chi^{2}(41)=114.17$, $p<.001 ;$ CFI $=0.96$; SRMR $=.04$; RMSEA $=.09$. Academic achievement was unrelated to depression, and the paths from hyperactivity to all mediators and to depression were not statistically significant. As a result, the model was reevaluated after removing both academic achievement and hyperactivity. This model (see Figure 1) provided a good fit that was also more parsimonious, $\chi^{2}(16)=31.00, p=.01 ; \mathrm{CFI}=0.98 ; \mathrm{SRMR}=.04$ RMSEA $=.06$. There were significant associations between inattention and both peer problems and parent-child problems, which were, in turn, significantly associated with depression. The point estimate of the indirect effect of the inattention latent factor on depression was $.08(S E=.03), p=.003$, for peer problems and $.13(S E=.04), p<.001$, for parent-child problems, indicating that both measures of interpersonal disturbance independently significantly mediated this association. The direct effect of inattention on depression was no longer significant over and above the variables reflecting interpersonal problems.

Inclusion of ODD. Given the frequent overlap between ADHD and ODD and the relevance of ODD to the mediators and outcome assessed, we examined the above model with the inclusion of latent ODD as an additional predictor. The latent ODD and inattention factors were allowed to covary, as were the ODD and inattention subscales from the DISC-IV. Although the model RMSEA fell slightly outside the standard thresholds for acceptable fit, $\chi^{2}(36)=68.17, p=.001 ; \mathrm{CFI}=0.97$; SRMR $=.04$; RMSEA $=$ .062 , the results suggested independent effects of both inattention and ODD (see Figure 2). Whereas only ODD had a significant direct effect on depression, both inattention and ODD demonstrated indirect effects via peer problems and parent-child problems on depression, although the effect was marginal for ODD via peer problems. The point estimate of the indirect effect of the inattention latent factor on depression was .06 $(S E=.03), p=.04$, for peer problems and $.04(S E=.02), p=.05$, for parent-child problems, whereas the point estimate of the indirect effect of the ODD latent factor on depression was .04 $(S E=.02), p=.095$, for peer problems and $.10(S E=.04), p=.01$, for parent-child problems. 


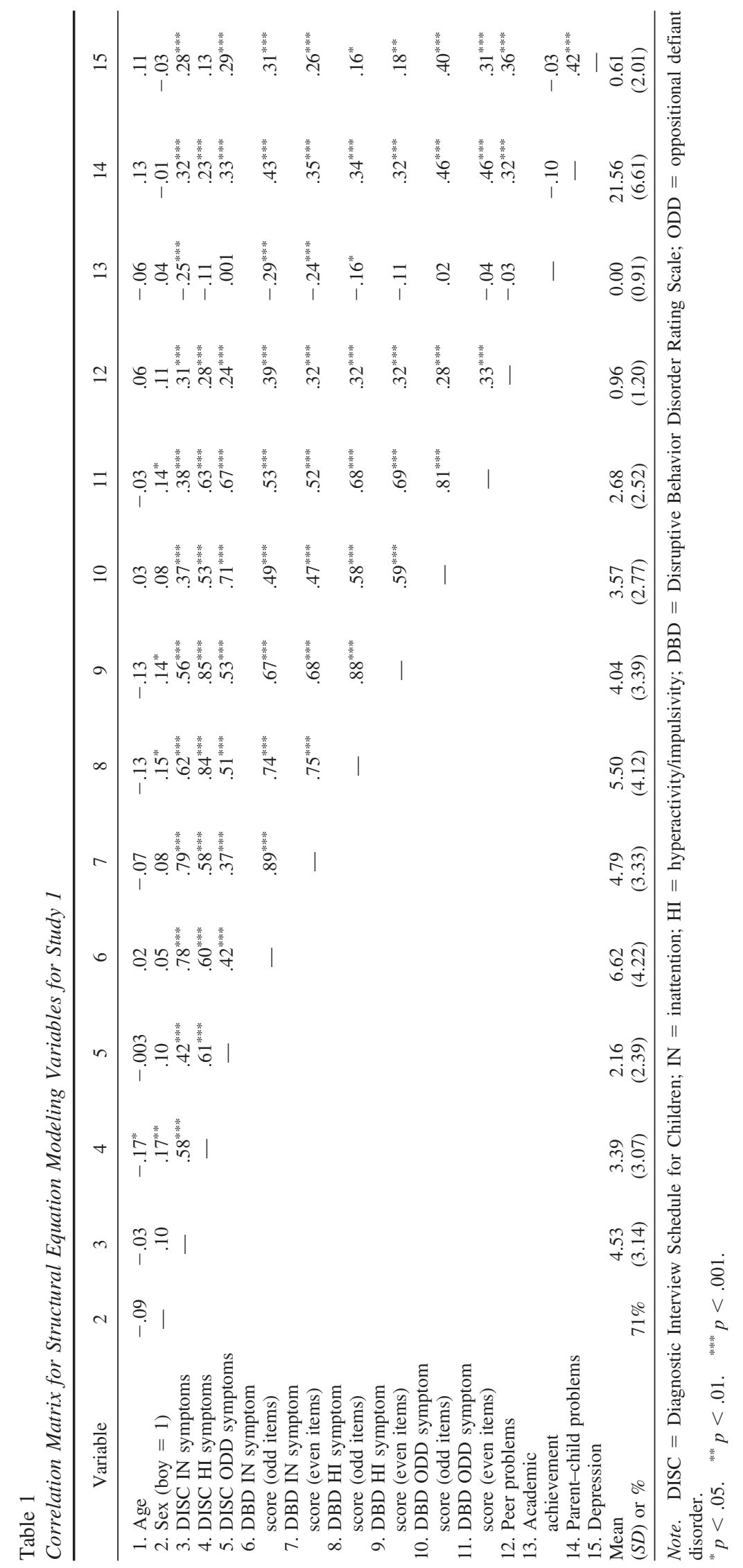




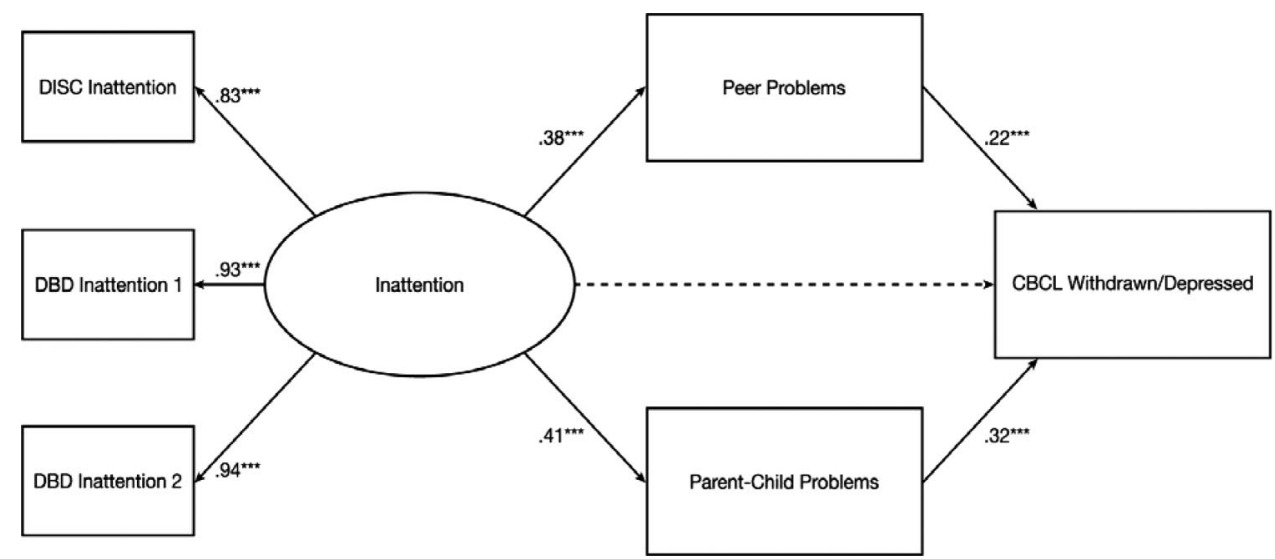

Figure 1. Model of the association of attention-deficit/hyperactivity disorder (ADHD) inattention with depression as mediated by peer rejection and parent-child problems $(n=229)$. DISC $=$ Diagnostic Interview Schedule for Children; DBD = Disruptive Behavior Disorder Rating Scale; CBCL $=$ Child Behavior Checklist . Standardized parameter estimations are shown; errors and covariances not shown. Nonsignificant paths are represented by dotted lines. ${ }^{* * * *} p<.001$.

Moderation by sex. Sex differences in the multiple mediation model were first examined by evaluating the difference in model fit between a model in which all paths were constrained to be equal across sex compared with a model in which all pathways were free to vary. Satorra-Bentler chi-square difference tests revealed no difference in model fit between the more restrictive and less restrictive models, $\chi_{\text {diff }}^{2}(7)=3.57, p=.83$. Second, there were no significant differences between boys and girls for any path coefficients or indirect effects.

Moderation by sex was then explored in the model in which ODD was included as a predictor. The Satorra-Bentler chi-square difference test revealed a marginally significant difference in model fit between the more restrictive and less restrictive models, $\chi_{\text {diff }}^{2}(11)=17.92, p=.08$. Specifically, ODD predicted parent-

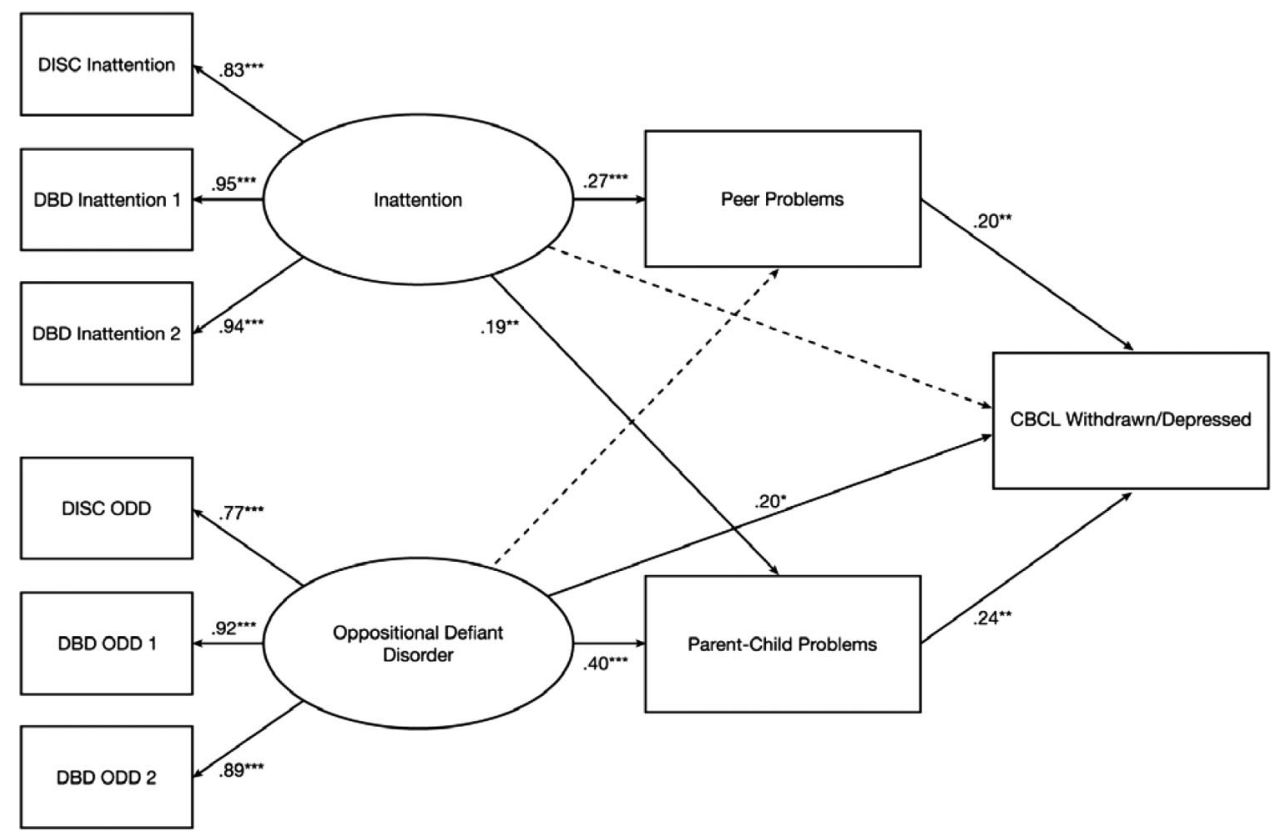

Figure 2. Model of the association of both attention-deficit/hyperactivity disorder (ADHD) inattention and oppositional defiant disorder with depression as mediated by peer rejection and parent-child problems $(n=$ 229). DISC = Diagnostic Interview Schedule for Children; DBD = Disruptive Behavior Disorder Rating Scale; $\mathrm{CBCL}=$ Child Behavior Checklist. Standardized parameter estimations are shown; errors and covariances not shown. Nonsignificant paths are represented by dotted lines. ${ }^{*} p<.05 .{ }^{* *} p<.01 .{ }^{* * * *} p<.001$. 
child problems more strongly for girls than for boys (unstandardized difference $=0.47, p<.05 ; \beta=.56, S E=.08, p<.001$, for girls; $\beta=.35, S E=.08, p<.001$, for boys). ODD also predicted peer problems for girls $(\beta=.47, S E=.16, p<.01)$; however, this pathway was nonsignificant for boys $(\beta=.09, S E=.10, p=.34)$. Another significant sex difference was found in which parentchild problems significantly mediated the association between ODD and depression for girls (estimate $=.39, S E=.14, p<.01$ ), but not for boys (estimate $=.07, S E=.04, p=.12$ ).

\section{Discussion}

The results of Study 1 suggest that both peer and parent-child difficulties independently mediated the association between inattention and depressive symptoms. The results affirm the importance of interpersonal difficulties in the prediction of depression. However, contrary to expectations, academic achievement was not a significant mediator. These findings were not moderated by the child's sex. The inclusion of ODD in the model revealed that both inattention and ODD were independent indirect predictors of depression via both peer problems and parent-child problems. These findings are in concert with previous evidence that ADHD is associated with depression similarly in young children (ages 6-9 years) with and without comorbid ODD (see Ostrander et al., 2006). In addition, the consequences of ODD were more significant for girls than boys, with girls experiencing more peer problems, parent-child problems, and, indirectly, depression, as a function of their ODD. Although these results are notable, the cross-sectional design and lack of youth self-report are limitations.

\section{Study 2}

It is unknown whether the associations between attention problems, interpersonal difficulties, and depression are robust across development, and whether Study 1 findings would replicate using measures of depression symptoms commonly used in clinical studies (i.e., Beck Depression Inventory) and using different, but more diverse, measures of academic, parent-child, and peer functioning. Study 2 attempted to replicate and extend the findings of Study 1 in a longitudinal high-risk community sample in which children of depressed mothers were overrepresented. Children in this sample were followed from birth to age 20 years, allowing for assessment across development and by multiple informants (i.e., self, mother, and teacher).

\section{Method}

Participants. Participants were 472 individuals (44\% male; age 20 years) from Queensland, Australia, followed from birth to age 20 years. These individuals were part of a larger birth cohort study, the Mater-University Study of Pregnancy (Keeping et al., 1989), designed to examine how conditions during pregnancy affect children's development up to age 5 years. Of the more than 7,000 mother-child pairs that participated in the original study, 815 were selected for follow-up at youth age 15 years. For further information regarding procedures of sample recruitment and screening, see Hammen, Shih, and Brennan (2004). Of these participants, 706 ( $87 \%$ of the sample) were retained for follow-up at youth age 20 years. Attrition was largely due to refusal to participate or failure to be located or scheduled. The sample for the present analyses consisted of the 472 individuals who, in addition to having self- and maternal-reported data, also had teacherreported data on social functioning when youths were 15 years old, which allowed for a more complete assessment of interpersonal functioning at age 15 years. This subsample did not differ from the original sample of 815 on childhood attention problems, $t(764)=$ $-1.00, p=.31$, depression diagnosis by age 15 years, $\chi^{2}(1)=$ $0.04, p=.92$, or any age 15 indicators of interpersonal functioning included in the current model. However, the current sample had lower levels of academic difficulties (e.g., class failures, school withdrawal) at age 15 years than those not included in the current sample, $t(656)=4.80, p<.001$.

Procedure. At participants' age 5 years, mothers completed rating scales pertaining to their health, attitudes, parenting style, and children's behavior, including selected questions from the CBCL (Achenbach, 1991)

At ages 15 and 20 years, participants and their mothers completed extensive interview and questionnaire sessions. Participants all gave informed consent, or assent in the case of minors, and the relevant institutional review/ethics panels of the University of Queensland, University of California, Los Angeles, and Emory University approved the research protocols.

At age 15 years, participants and mothers were also asked permission to allow researchers to collect information from participants' teachers. Participating teachers completed the Teacher's Report Form (Achenbach, 1991) and an additional questionnaire regarding academic and social functioning of the participant.

\section{Measures.}

Age 5 behavior and emotion problems. At youth age 5 years, mothers completed a modified version of the CBCL (Achenbach, 1991) regarding their children's emotional states and behaviors. This abbreviated version of the CBCL was developed by Najman et al. (1997) and included 33 of the 118 items from the full-length CBCL. Such items were selected based on resource constraints to reduce participant burden. Reliability estimates indicate that the psychometric properties of the modified CBCL are similar to those of the full version. For example, scores on the shortened version of the Externalizing subscale of the CBCL are strongly correlated with scores from the full version ( $r=.94$; Najman et al.). Three subscales of the modified CBCL were relevant to the current study: Attention Problems, Aggression, and Internalizing subscales.

Age 15 academic problems. Academic problems were assessed at age 15 years using the Academic Stress section of the University of California, Los Angeles Life Stress Interview (LSI; Hammen \& Brennan, 2001). The LSI is a semistructured interview that assesses stress in various domains of functioning, including social relationships, family relationships, and school or work. For each domain, trained interviewers query the participant about his or her functioning. The interviewers then determine a rating of stress/functioning on the basis of participants' reports, with scores ranging from 1 to 5 , with half points permitted. In the case of academic functioning, a score of 1 reflects "superior performance in all areas: honors," and a score of 5 is given when an individual is "doing very poorly academically, has failed 3 or more subjects, has full-time placement in special classes, or has dropped out of school for academic reasons." Reliabilities for this measure were 
based on independent judges' ratings of 88 audiotaped interviews. In the full sample of individuals followed to age 15 years, the intraclass correlation (ICC) for ratings on this measure was .94. Scores on this measure were significantly correlated with teacher reports of participants' academic performance in their own class at $r=.56$ (see Adrian \& Hammen, 1993; Rao, Hammen, \& Daley, 1999 , for more information regarding the psychometric properties of the LSI).

Age 15 peer problems. Impairment in peer relationships was assessed at age 15 years using teacher-report data, interview data from the LSI, and self-report data. In the current analyses, these three indicators of social impairment were used to create a latent factor of peer problems.

Teachers were asked to describe the participant's age 15 functioning, including one item on the youth's popularity with peers rated from 1 (not at all popular) to 7 (extremely popular). This item served as one indicator of peer problems.

Information about participants' social functioning was also assessed using the Social Life domain of the LSI. Participants were queried about the size of their social circle, quality of social relationships, and frequency of social interaction. As with all domains of the LSI, interviewers gave participants a score from 1 to 5. A score of 1 reflects a social life including many friends, frequent engagement in social activities, and no conflict in social situations, and a score of 5 is indicative of no friends, rejection by peers, or frequent and severe conflict with friends or acquaintances. The ICC for reliability on this measure was .63. Supporting the validity of this measure, significant correlations have been found between the LSI-Social Life scores and ratings of peer acceptance or rejection and popularity assessed by homeroom teachers (see Hammen, Brennan, \& Keenan-Miller, 2008).

Third, participants were asked to complete the Self-Perception Profile for Adolescents (Harter, 1988). Used in the current study was the Social Acceptance subscale of this measure, which consists of five items (each rated on a scale from 1 to 4) regarding perceived acceptance by peers, ease of making friends, and likeability.

Age 15 parent-child problems. Parent-child problems were assessed using three different measures at age 15 years: (1) chronic stress in the Mother-Child Relationship domain of the LSI administered to participants' mothers, (2) chronic stress in the Family Domain of the LSI administered to participants, and (3) participant reports of mothers' controlling parenting behaviors. These three measures were used as indicators of an underlying latent variable of parent-child problems.

First, the LSI was conducted with participants' mothers during the age 15 assessment. The domain of the LSI that assessed parent-child relationship stress queried mothers about the quality of the parent-child relationship, including closeness, conflict, and the child's compliance with rules. On the behaviorally anchored 1-5 scoring scale, a score of 1 represents an exceptionally close and effective parenting relationship with minimal chronic stress, and a 5 represents a poor parent-child relationship marked by conflict and poor monitoring or control over the youth. The ICC of reliability among raters was .82 .

Participants also completed a domain of the LSI regarding their family relationships, including factors such as closeness, communication, and conflict resolution. A score of 1 represents an exceptional quality relationship with all members of the family, and a score of 5 reflects markedly poor relationship quality and significant problems. The ICC of interrater reliability was .84 .

Participants additionally completed the Psychological Control subscale of the Children's Report of Parental Behavior Inventory (Schludermann \& Schludermann, 1988). This scale includes items such as "wants to control whatever I do" and "is always trying to change me." Children's Report of Parental Behavior Inventory subscales have shown good reliability and convergent validity (e.g., parental overinvolvement; Safford, Alloy, \& Pieracci, 2007).

Age 20 depressive symptoms. Participants' depressive symptoms were assessed at age 20 years using the Beck Depression Inventory-II (Beck, Steer, \& Brown, 1996). The Beck Depression Inventory-II is a well-validated and widely used 21-item self-report measure of depressive symptomatology. Questions cover symptoms of depression including low mood, appetite changes, and suicidal ideation, among others.

\section{Results}

Proposed structural model. Descriptive statistics and bivariate correlations among all observed variables are presented in Table 2. To test study hypotheses, we evaluated a multiple mediation model based on childhood attention problems directly predicting depressive symptoms in early adulthood and indirectly predicting depressive symptoms via peer problems, academic problems and parent-child problems. Academic problems were included in the model as an observed variable, whereas both peer problems and parent-child problems were included as latent factors with three indicators each, as explained in the Method section. As with Study 1, all observed variables were converted to $z$-scores prior to analyses to facilitate interpretation of results. To account for nonnormality in several variables, we used robust maximum likelihood procedures to obtain model estimates.

Multiple mediation. To examine peer problems, academic problems, and parent-child problems as mediators of the association between youth attention problems and early adult depressive symptoms, we evaluated the full proposed structural model. The model controlled for child's sex and internalizing symptoms at age 5 years, which diminished the possibility that any effects of age 5 attention problems on later depression were merely a result of initial comorbidity of attention problems and internalizing difficulties at age 5 years.

Although the model was an acceptable fit to the data by some fit statistics (CFI $=0.90$, SRMR $=.50)$, the RMSEA (.064) was slightly higher than the acceptable cutoff. The chi-square test statistic was significant, $\chi^{2}(34)=99.84, p<.001$; however, chi-square test statistics are often significant with large samples. Parameter estimates revealed that, whereas attention problems predicted all three mediators, depressive symptoms were predicted by peer and parent-child problems only. Consistent with Study 1, academic problems were unrelated to later depressive symptoms $(\beta=.05, S E=.06, p=.43)$. For this reason, the academic problems variable was excluded from the model.

When the model was reevaluated without academic problems (i.e., peer problems and parent-child problems as the two mediators), the model adequately fit the data, $\chi^{2}(28)=71.59, p<.001$; $\mathrm{CFI}=0.93$, SRMR $=.04 ;$ RMSEA $=.058$ (see Figure 3 ). The direct path from childhood attention problems to adult depressive symptoms was nonsignificant. Attention problems significantly 


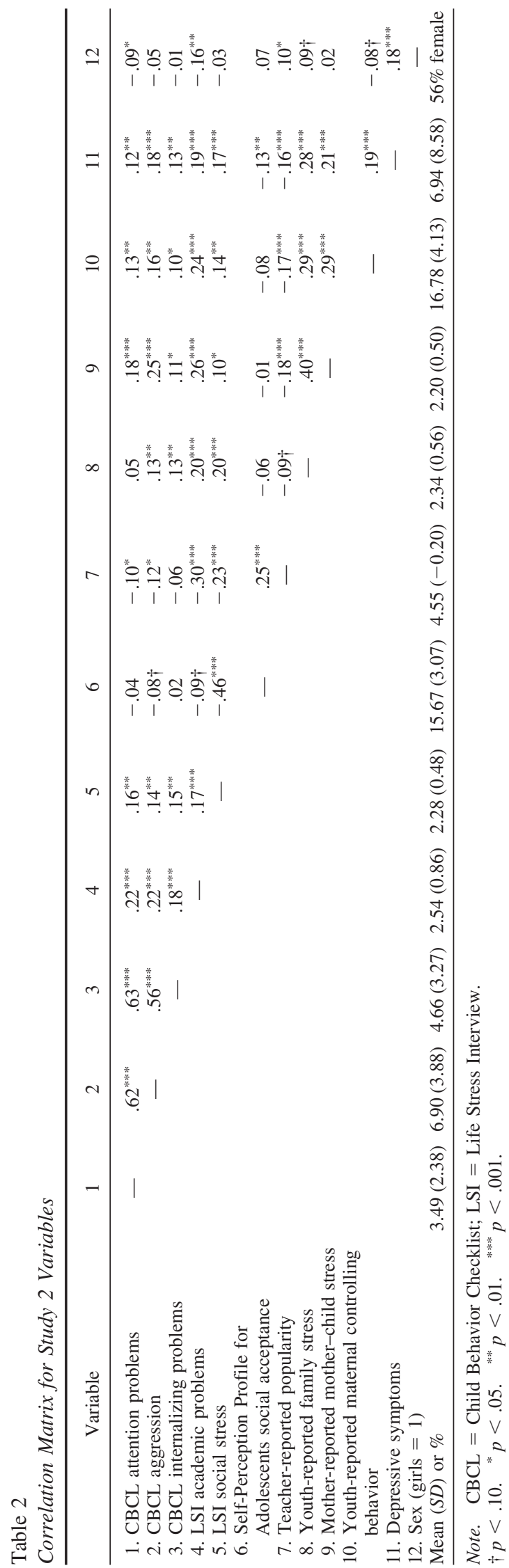

predicted peer problems and parent-child problems, which, in turn, significantly predicted depressive symptoms. Analyses revealed a significant specific indirect effect of attention problems on depressive symptoms via parent-child problems (point estimate $=$ $.07, S E=.03, p<.05)$. In addition, there was a marginal specific indirect effect of attention problems on depressive symptoms via peer problems (point estimate $=.03, S E=.01, p=.08$ ) ${ }^{1}$

Inclusion of ODD. To account for co-occurring ODD/aggression in predictions of impaired interpersonal functioning and subsequent depression symptoms, we reproduced the aforementioned multiple mediation model, except we included childhood aggression as a second predictor of the two mediators and outcome variable (see Figure 4). This model adequately fit the data, $\chi^{2}(32)=78.59, p<.001 ; \mathrm{CFI}=0.95 ;$ SRMR $=.04 ;$ RMSEA $=$ .056. In contrast to the first multiple mediation model, attention problems did not significantly predict peer problems or parentchild problems. Childhood aggression, however, significantly predicted parent-child problems but not peer problems. Examination of indirect effects revealed that parent-child problems significantly mediated the association of childhood aggression and adult depressive symptoms $(\beta=.10, S E=.04, p<.01)$. No further mediation was supported, and neither childhood inattention nor childhood aggression directly predicted age 20 depressive symptoms.

Moderation by sex. Satorra-Bentler chi-square difference tests evaluated potential sex differences. In the model with attention problems as the only predictor, there was no significant difference in model fit, $\chi_{\text {diff }}^{2}(8)=12.48, p=.13$. However, the path from parent-child problems to depressive symptoms differed across sex (unstandardized difference $=0.68, p<.05$ ), such that parent-child problems significantly predicted depressive symptoms for girls $(\beta=.77, S E=.20, p<.001)$, but not for boys $(\beta=$ $.10, S E=.21, p=.65)$. There were no significant differences in indirect effect point estimates across sex.

For the multiple mediation model in which both childhood attention problems and aggression were included as predictors, the Satorra-Bentler chi-square difference test revealed a marginally significant difference between the restricted and unrestricted models, $\chi_{\text {diff }}^{2}(13)=21.36, p=.07$. Further analysis revealed a significant difference between boys and girls in the relationship between aggression and parent-child problems (unstandardized difference $=0.22, p<.05)$, such that parent-child problems were predicted by childhood aggression for girls $(\beta=.43, S E=.10$, $p<.001)$, but not for boys $(\beta=.13, S E=.09, p=.14)$. In addition, depression was predicted by parent-child problems for girls $(\beta=.45, S E=.09, p<.001)$, but not for boys $(\beta=.06$, $S E=.14, p=.67)$. Overall, the indirect path from aggression to depression via parent-child problems was significant for girls (estimate $=.23, S E=.08, p<.01)$, but not for boys (estimate $=$ $.01, S E=.02, p=.70)$

\footnotetext{
${ }^{1}$ This multiple mediation model was rerun controlling for maternal depression, which had no effect on the pattern or significance of study findings. In addition, this model was rerun controlling for age 15 depressive symptoms. Whereas parent-child problems remained a significant mediator of the relationship between attention problems and depression, peer problems no longer met criteria for mediation in this case.
} 


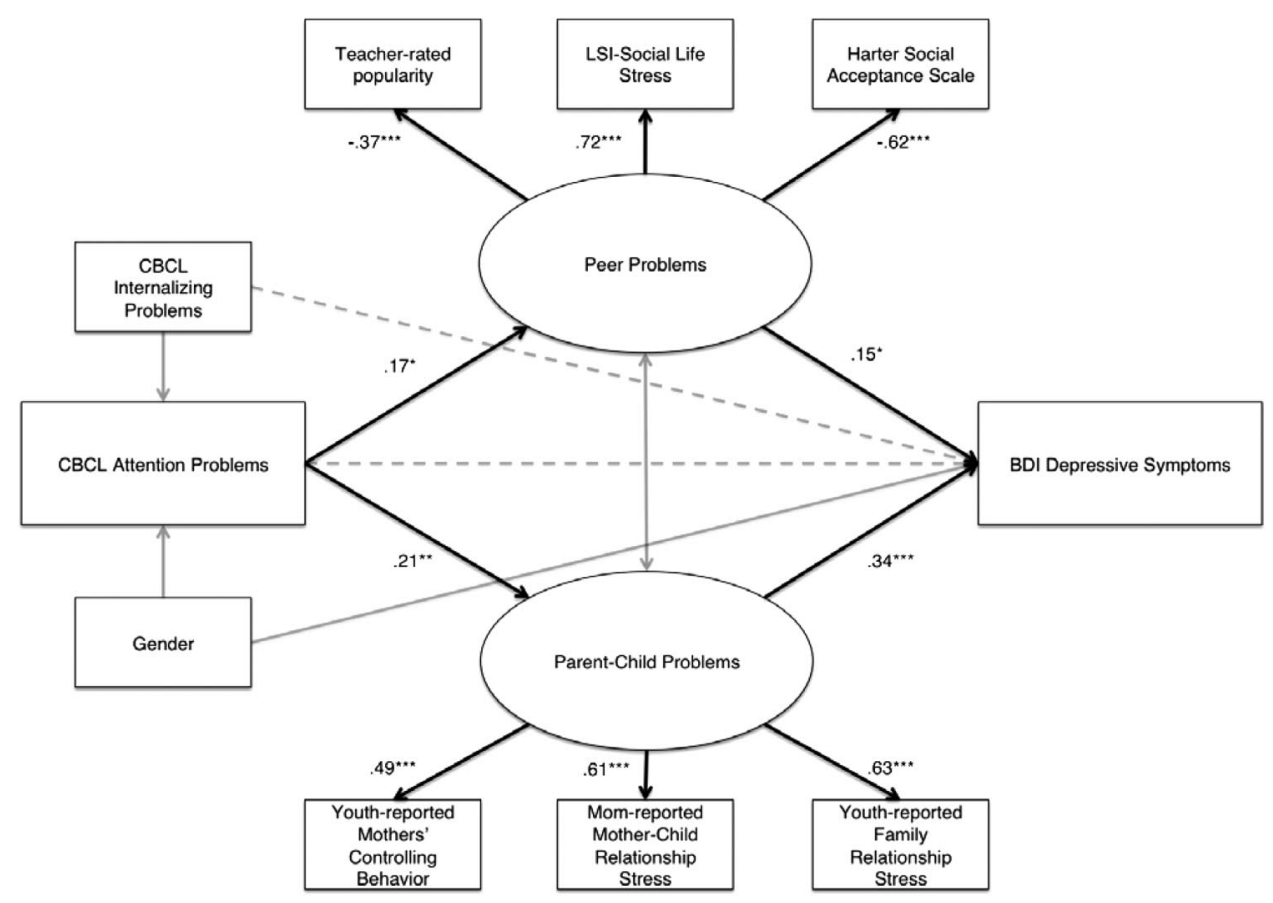

Figure 3. Final model of the association between age 5 attention problems and age 20 depressive symptoms. Model excludes academic problems due to nonsignificant pathways in the original model. Model includes peer problems and parent-child problems as mediators, as well as age 5 internalizing problems and sex as statistical controls. $\mathrm{CBCL}=$ Child Behavior Checklist; $\mathrm{LSI}=$ Life Stress Interview; BDI = Beck Depression Inventory. Standardized parameter estimates are shown. Parameter estimates unrelated to study hypotheses are excluded from the figure for ease of readability. Nonsignificant paths are represented by dotted lines. ${ }^{*} p<.05 .{ }^{* *} p<$ $.01{ }^{* * * *} p<.001$

\section{Discussion}

As in Study 1, multiple mediation analyses revealed that academic functioning was not a significant unique mediator in the association between attention problems and depression. However, adolescent peer and parent-child problems each predicted later depressive symptoms and were predicted by early attention problems. Parent-child problems significantly mediated the relationship between attention problems and depression, whereas peer problems marginally significantly mediated this relationship. Notably, when childhood aggression, a proxy for ODD symptoms, was included in the model, attention problems no longer predicted these mediators. Instead, childhood aggression significantly predicted parent-child problems and, in turn, adult depression symptoms. This nonsignificant effect of attention problems when accounting for childhood aggression differs from the findings of Study 1. Finally, parent-child problems significantly predicted depression for girls, but not for boys, and childhood aggression was only predictive of parent-child problems for girls. This suggests that the significant mediating role of parent-child problems in the full sample may reflect the relatively strong relationship between these variables among girls.

\section{General Discussion}

Using two independent but complementary samples, we explored the association between attention problems and depression, with particular consideration of the interpersonal and functional impairments that may contribute to the development of depressive symptoms among children with elevated inattention. Study 1 examined the mediating roles of peer problems, academic achievement, and parent-child problems in the concurrent association of ADHD and depression in a sample of school-age children with and without ADHD. The use of rigorous and reliable measures of ADHD symptoms allowed for the separate examination of inattention versus hyperactivity symptoms, as well as ODD symptoms, and their unique associations with academic and psychosocial impairment as well as depressive symptoms. Study 2 also examined peer, academic, and parent-child problems in a prospective longitudinal sample of children followed from birth to age 20 years whose mothers disproportionately had clinical depression histories. The sample allowed for exploration of the ADHD-depression relationship and its mediating factors across three time points, spanning from early childhood to young adulthood, and included multiple informants on child's behavior and a well-validated measure of depressive symptoms.

We believe the most substantial finding is that, in both samples, parent-child problems significantly mediated the relationship between attention problems and depression over and above the potential effects of both peer and academic domains. Thus, dualfailure models of externalizing problems and later depression appear to be omitting this important factor. Previous literature has shown elevated rates of parent-child problems in parents of chil- 


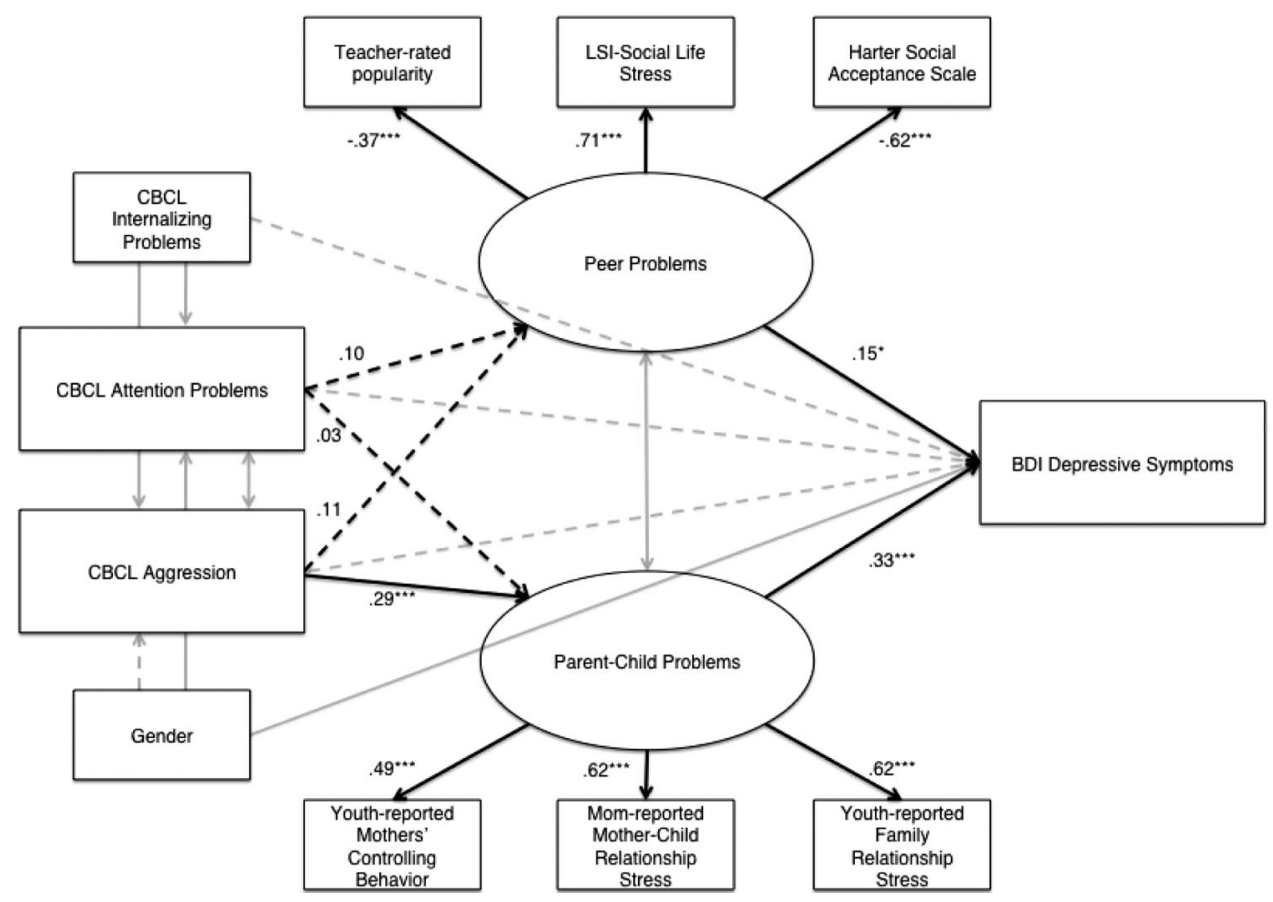

Figure 4. Final model of the association between age 5 attention problems, age 5 aggression, and age 20 depressive symptoms. Model includes peer problems and parent-child problems as mediators, as well as age 5 internalizing problems and sex as statistical controls. $\mathrm{CBCL}=$ Child Behavior Checklist; LSI $=$ Life Stress Interview; BDI $=$ Beck Depression Inventory. Standardized parameter estimates are shown. Parameter estimates unrelated to study hypotheses are excluded from the figure for ease of readability. Nonsignificant paths are represented by dotted lines. ${ }^{*} p<.05 .{ }^{* *} p<.01 .{ }^{* * * *} p<.001$.

dren with comorbid ADHD and depression (Deault, 2010), an association between ADHD and parent-child problems (e.g., Barkley et al., 1991), and an association between parent-child problems and depression (e.g., McLeod, Weisz, \& Wood, 2007). Given the stress associated with parenting a child with ADHD (Barkley et al., 1992), these parents may have difficulty implementing effective parenting strategies, have greater conflict with their children, and convey greater rejection and hostility to their children (Johnston \& Mash, 2001; Lifford et al., 2008, 2009). In turn, stressful conflict and perceived lack of support from parents may contribute to the onset of depressive symptoms (e.g., Stice, Ragan, \& Randall, 2004). Further research is needed to determine the specific components of parent-child problems that may be responsible for the relationship between ADHD and depression.

Peer problems significantly mediated the ADHD-depression relationship in Study 1 and marginally mediated the ADHDdepression relationship in Study 2. Thus, beyond the wellestablished peer difficulties among children with ADHD (Hoza et al., 2005), difficulties with peer relationships may contribute to depressive symptoms (see Hirschfeld et al., 2000, for a review). Children with ADHD frequently overestimate their social competence and functioning in other domains, a phenomenon known as positive illusory bias (see Owens, Goldfine, Evangelista, Hoza, \& Kaiser, 2007, for a review). Such inflated positive self-perceptions may serve as a double-edged sword: On the one hand, these perceptions may inhibit children's ability to incorporate critical feedback from others in order to change their social behaviors and improve their relationships (Colvin \& Block, 1994). On the other hand, positive self-perceptions protect children with ADHD from the development of depression (McQuade, Hoza, Murray-Close, Waschbusch, \& Owens, 2011). Notably, positive illusory bias is not found among children with comorbid depression (Hoza, Waschbusch, Pelham, Molina, \& Milich, 2000), potentially making this subgroup more attuned to negative peer relationships. It may be that as children become increasingly proficient at understanding how others view them, the protective effect associated with the positive illusory bias may be replaced by more stable negative self-schemata. One notable limitation of both studies was the lack of parallel self-report and observer-report measures to allow for a comparison between self-appraisal of interpersonal functioning and actual interpersonal functioning. The discrepancy between one's cognitions about social functioning and one's actual social performance may be crucial to the development of depression.

Interestingly, neither study found that academic functioning significantly mediated the association of ADHD and depression when peer problems and parent-child problems were treated as simultaneous mediators. Yet, there are limitations in both studies' measures of academic functioning, as both standardized assessment and youth interview are unlikely to perfectly capture school performance. In addition, parent report was used for all variables included in Study 1, with the exception of academic achievement, reducing the likelihood of shared variance due to methodological issues alone. However, validation data supported the use of the LSI 
in Study 2, as academic performance scores were corroborated by teacher reports. It should be noted that in Study 1, although academic functioning was associated with attention problems, it was uncorrelated with depression. This is counter to existing literature (Herman, Lambert, Reinke, \& Ialongo, 2008), and the use of a measure that assesses ability rather than actual classroom performance may underlie this finding. In Study 2, academic functioning was correlated with both attention and depression measures, yet, in the full model when other correlated variables were also included, academic functioning did not uniquely predict depression or the ADHD-depression relationship. Previous work has also documented a relative weakness of academic competence as a mediator of child problems to depression compared with peer problems (e.g., Blechman, McEnroe, Carella, \& Audette, 1986; Patterson \& Stoolmiller, 1991). Future studies will benefit from multi-informant measures of academic performance to confirm this domain's secondary role to interpersonal difficulties in predictions of depressive symptoms.

Study 1 also separately examined inattention and hyperactivity to determine the relative contribution to interpersonal problems and depression. Inattention, but not hyperactivity, was related to peer problems, parent-child problems, and depression symptoms. Meta-analytic evidence suggests that whereas hyperactivity is more strongly associated with negative peer regard than inattention, social isolation is more strongly associated with inattention than hyperactivity (Willcutt et al., 2012). As social withdrawal has predicted risk for depressive symptoms by way of peer difficulties (e.g., Katz, Conway, Hammen, Brennan, \& Najman, 2011), it is possible that there is a similar trajectory for children with attention problems. Given that SEM included predictors examined simultaneously, it is likely that the effect of inattention resulted in the nonsignificant association between hyperactivity and relevant outcomes, despite significant bivariate correlations between hyperactivity and both peer problems and parent-child problems.

The present study also explored the independent roles of ADHD and ODD in the development of depression. Results from Study 1 suggest that only ODD is a direct predictor of depression. However, inattention remained an important independent indirect predictor of depression through peer and parent-child problems. ODD, on the other hand, demonstrated a significant indirect effect on depression via parent-child problems and a marginal effect via peer problems. The impact of aggression in Study 2 was less clear. The inclusion of baseline aggression resulted in the loss of a significant indirect effect of attention problems on depression, and neither inattention nor aggression demonstrated a significant indirect effect via peer problems. Only parent-child problems remained a significant mediator of the aggression to depression association. Clearly, the potential role of ODD/aggression in studies of ADHD remains an important issue in developmental psychopathology, and the present studies provide further evidence that inattention is an important risk factor for depression independent of ODD, but that the inclusion of conduct problems may complicate the ability to obtain direct effects from ADHD. Although distinguishing the independent roles of ADHD and ODD remains an important theoretical question, there is increasing evidence that individuals with ADHD + ODD comorbidity are at the highest risk for a number of negative outcomes (e.g., Carlson, Tamm, \& Gaub, 1997; Humphreys \& Lee, 2011).
No sex differences were found in the relationship between ADHD and interpersonal problems or indirect effects of ADHD on depression by way of interpersonal problems. However, both studies revealed significant sex differences in the indirect effect of ODD on depression through parent-child problems, such that ODD symptoms predicted these negative outcomes more strongly for girls than for boys. Although the rate of ODD is lower in girls compared with boys (Lahey, Miller, Gordon, \& Riley, 1999), girls with conduct problems are more likely to have comorbid disorders (Robins, 1986), known as the gender paradox. It may be that parent-child relationships are more central to the development of comorbidity, including depression, in girls with elevated ODD symptoms. Study 2 also found a significant sex difference in the effect of parent-child relationship problems on depressive symptoms in which parent-child problems significantly predicted depressive symptoms among girls, but not boys. This is consistent with previous literature suggesting that girls are more likely than boys to develop depression in response to interpersonal difficulties (see Leadbeater, Blatt, \& Quinlan, 1995). In light of meta-analytic evidence that boys are much more likely to meet diagnostic criteria for $\mathrm{ADHD}$ and that girls with $\mathrm{ADHD}$ have more co-occurring internalizing symptoms (Gershon, 2002), these associations may be sex specific.

Overall, similar findings were noted of the ADHD-depression relationship and its mediators in two complementary samples. Study 1 was limited by its cross-sectional design, but included rigorous measures of $\mathrm{ADHD}$, including separate tests of inattention and hyperactivity. Although Study 2 had a single measure of attention problems, it was strengthened by its prospective design spanning multiple developmental stages, data from multiple informants, and reliable and valid measurement of depressive symptoms. Thus, for the most part, where each study was lacking, the other study improved on those limitations. Despite potentially important differences in the etiology and presentation of child-, adolescent-, and adult-onset depression (e.g., Kaufman, Martin, King, \& Charney, 2001), both final models suggested that ADHD may affect depression at different developmental stages via similar mechanisms. In addition, although it is unclear at what age elevated depression levels presented, it is significant that the indirect effect of attention problems on depression via parent-child problems remained following the stringent inclusions of both baseline and age 15 depression measures.

Several important limitations should be considered, including the exclusive use of maternal reports of attention problems in both studies. Maternal psychopathology, such as depression, has been found to predict negatively biased reports of child ADHD symptoms and behavior problems (Chi \& Hinshaw, 2002). On the other hand, emotionally healthy mothers tend to underestimate their children's emotional and behavioral problems, relative to children's self-reports (Najman et al., 2001). In addition, although there were efforts in Study 2 to control for relevant baseline predictors, we were unable to include baseline peer functioning in our models as other studies have done (i.e., Herman et al., 2008). Importantly, Herman and colleagues (2008) documented a link between academic competence and depression after controlling for baseline depression, peer relations, attention problems, and conduct problems. The rigorous inclusion of baseline covariates in future research would provide the most conservative test for examining mediation of the ADHD-depression relationship. 
One further limitation was the length of time that elapsed between the age 15 and age 20 assessments in Study 2. It may be the case that 5 years is too long to expect mood-related consequences to persist secondary to interpersonal or academic difficulties. For example, failing a class in high school, although likely to negatively affect mood in the short term, may have little effect on long-term mental health outcomes. This 5-year period between assessments may be at least partially responsible for the contrast between our nonsignificant findings related to academic difficulties and the significant findings of previous research on the dualfailure model (e.g., Patterson \& Stoolmiller, 1991). An alternative consideration, proposed by Cole (1991), is that the value placed on academic functioning may decline in adolescence, as interpersonal factors increase in salience. In this case, despite the association between ADHD and poorer academic functioning, it is less likely that (negative) self-schema is tied to this domain. The changing priorities across development suggest that the mediators of the association between attention problems and depression should change over development, deemphasizing the role of failure related to academic and parent-child domains and prioritizing peer domains.

The two complementary studies included in this report provide significant evidence that peer problems and parent-child problems, but not academic functioning, play an important role in the relationship between attention problems and depression. Thus, these two aspects of interpersonal functioning may be central targets of intervention for children with ADHD. In line with both failure and competency models, treatment programs that emphasize improving competence may be particularly useful in children with ADHD (e.g., The Incredible Years; Webster-Stratton, 1992). Outcome research from this program found that child internalizing scores decreased following treatment (Webster-Stratton \& Herman, 2008), which indicates that such treatment programs may be promising for addressing depression in children with disruptive behavior problems.

\section{References}

Abidin, R. R. (1995). Parenting Stress Index (3rd ed.). Odessa, FL: Psychological Assessment Resources.

Achenbach, T. M. (1991). Integrative guide to the 1991 CBCL, YSR, and TRF profiles. Burlington, VT: University of Vermont, Department of Psychiatry.

Achenbach, T. M., \& Rescorla, L. A. (2001). Manual for the ASEBA School-Age Forms and Profiles. Burlington, VT: University of Vermont Research Center for Children, Youth, and Families.

Adrian, C., \& Hammen, C. (1993). Stress exposure and stress generation in children of depressed mothers. Journal of Consulting and Clinical Psychology, 61, 354-359. doi:10.1037/0022-006X.61.2.354

American Psychiatric Association. (2000). Diagnostic and statistical manual of mental disorders (4th ed., text rev.). Washington, DC: Author.

Anastopoulos, A., Shelton, T., DuPaul, G., \& Guevremont, D. (1993). Parent training for attention deficit hyperactivity disorder: Its impact on parent functioning. Journal of Abnormal Child Psychology, 21, 581596. doi:10.1007/BF00916320

Anderson, J. C., Williams, S., McGee, R., \& Silva, P. A. (1987). DSM-III disorders in preadolescent children: Prevalence in a large sample from the general population. Archives of General Psychiatry, 44, 69-76. doi:10.1001/archpsyc.1987.01800130081010

Barkley, R. A., Anastopoulos, A. D., Guevremont, D. C., \& Fletcher, K. E. (1992). Adolescents with ADHD: Mother-adolescent interactions, fam- ily beliefs and conflicts, and maternal psychopathology. Journal of Abnormal Child Psychology, 20, 263-288. doi:10.1007/BF00916692

Barkley, R. A., Fischer, M., Edelbrock, C. S., \& Smallish, L. (1991). The adolescent outcome of hyperactive children diagnosed by research criteria: III. Mother-child interactions, family conflicts and maternal psychopathology. Journal of Child Psychology and Psychiatry and Allied Disciplines, 32, 233-255. doi:10.1111/j.1469-7610.1991.tb00304.x

Beck, A. T., Steer, R. A., \& Brown, G. K. (1996). Manual for the Beck Depression Inventory-II. San Antonio, TX: Psychological Corporation.

Biederman, J., Ball, S. W., Monuteaux, M. C., Mick, E., Spencer, T. J., McCreary, M., . . . Faraone, S. V. (2008). New insights into the comorbidity between $\mathrm{ADHD}$ and major depression in adolescent and young adult females. Journal of the American Academy of Child \& Adolescent Psychiatry, 47, 426-434. doi:10.1097/CHI.0b013e31816429d3

Biederman, J., Mick, E., \& Faraone, S. V. (1998). Depression in attention deficit hyperactivity disorder (ADHD) children: "True" depression or demoralization? Journal of Affective Disorders, 47, 113-122. doi: 10.1016/S0165-0327(97)00127-4

Biederman, J., Newcorn, J., \& Sprich, S. (1991). Comorbidity of attention deficit hyperactivity disorder with conduct, depressive, anxiety, and other disorders. The American Journal of Psychiatry, 148, 564-577.

Blechman, E. A., McEnroe, M. J., Carella, E. T., \& Audette, D. P. (1986). Childhood competence and depression. Journal of Abnormal Psychology, 95, 223-227. doi:10.1037/0021-843X.95.3.223

Bollen, K. A. (1989). Structural equations with latent variables. New York, NY: Wiley.

Capaldi, D. M. (1991). Co-occurrence of conduct problems and depressive symptoms in early adolescent boys: I. Familial factors and general adjustment at Grade 6. Development and Psychopathology, 3, 277-300. doi:10.1017/S0954579400005319

Carlson, C. L., Tamm, L., \& Gaub, M. (1997). Gender differences in children with ADHD, ODD, and co-occurring ADHD/ODD identified in a school population. Journal of the American Academy of Child \& Adolescent Psychiatry, 36, 1706-1714. doi:10.1097/00004583199712000-00019

Chi, T. C., \& Hinshaw, S. P. (2002). Mother-child relationships of children with ADHD: The role of maternal depressive symptoms and depression-related distortions. Journal of Abnormal Child Psychology, 30, 387-400. doi:10.1023/A:1015770025043

Cole, D. A. (1990). Relation of social and academic competence to depressive symptoms in childhood. Journal of Abnormal Psychology, 99, 422-429. doi:10.1037/0021-843X.99.4.422

Cole, D. A. (1991). Preliminary support for a competency-based model of depression in children. Journal of Abnormal Psychology, 100, 181-190. doi:10.1037/0021-843X.100.2.181

Colvin, C. R., \& Block, J. (1994). Do positive illusions foster mental health? An examination of the Taylor and Brown formulation. Psychological Bulletin, 116, 3-20. doi:10.1037/0033-2909.116.1.3

Deault, L. C. (2010). A systematic review of parenting in relation to the development of comorbidities and functional impairments in children with attention-deficit/hyperactivity disorder (ADHD). Child Psychiatry and Human Development, 41, 168-192. doi:10.1007/s10578-0090159-4

Dishion, T. J. (1990). Family ecology of boys' peer relations in middle childhood. Child Development, 61, 874-892. doi:10.2307/1130971

Eberhart, N. K., \& Hammen, C. L. (2006). Interpersonal predictors of onset of depression during the transition to adulthood. Personal Relationships, 13, 195-206. doi:10.1111/j.1475-6811.2006.00113.x

Ebesutani, C., Bernstein, A., Nakamura, B., Chorpita, B., Higa-McMillan, C., \& Weisz, J. (2010). Concurrent validity of the Child Behavior Checklist DSM-oriented scales: Correspondence with DSM diagnoses and comparison to syndrome scales. Journal of Psychopathology and Behavioral Assessment, 32, 373-384. doi:10.1007/s10862-009-9174-9 
Gershon, J. (2002). A meta-analytic review of gender differences in ADHD. Journal of Attention Disorders, 5, 143-154. doi:10.1177/ 108705470200500302

Hammen, C., \& Brennan, P. A. (2001). Depressed adolescents of depressed and nondepressed mothers: Tests of an interpersonal impairment hypothesis. Journal of Consulting and Clinical Psychology, 69, 284-294. doi:10.1037/0022-006X.69.2.284

Hammen, C., Brennan, P. A., \& Keenan-Miller, D. (2008). Patterns of adolescent depression to age 20: The role of maternal depression and youth interpersonal dysfunction. Journal of Abnormal Child Psychology, 36, 1189-1198. doi:10.1007/s10802-008-9241-9

Hammen, C., Shih, J. H., \& Brennan, P. A. (2004). Intergenerational transmission of depression: Test of an interpersonal stress model in a community sample. Journal of Consulting and Clinical Psychology, 72, 511-522. doi:10.1037/0022-006X.72.3.511

Harter, S. (1988). Manual for the Self-Perception Profile for Adolescents. Unpublished manuscript, University of Denver.

Henker, B., \& Whalen, C. K. (1999). The child with attention-deficit/ hyperactivity disorder in school and peer settings. In H. C. Quay \& A. E. Hogan (Eds.), Handbook of disruptive behavior disorder (pp. 157-178). New York, NY: Plenum Press. doi:10.1007/978-1-4615-4881-2_7

Herman, K. C., Lambert, S. F., Ialongo, N. S., \& Ostrander, R. (2007). Academic pathways between attention problems and depressive symptoms among urban African American children. Journal of Abnormal Child Psychology, 35, 265-274. doi:10.1007/s10802-006-9083-2

Herman, K. C., Lambert, S. F., Reinke, W. M., \& Ialongo, N. S. (2008). Low academic competence in first grade as a risk factor for depressive cognitions and symptoms in middle school. Journal of Counseling Psychology, 55, 400-410. doi:10.1037/a0012654

Hirschfeld, M. D., Montgomery, S. A., Keller, M. B., Kasper, S., Schatzberg, A. F., Möller, H., . . . Bourgeois, M. (2000). Social functioning in depression: A review. Journal of Clinical Psychiatry, 61, 268-275. doi:10.4088/JCP.v61n0405

Hoza, B., Mrug, S., Gerdes, A. C., Hinshaw, S. P., Bukowski, W. M., Gold, J. A., . . Arnold, L. E. (2005). What aspects of peer relationships are impaired in children with ADHD? Journal of Consulting and Clinical Psychology, 73, 411-423. doi:10.1037/0022-006X.73.3.411

Hoza, B., Waschbusch, D. A., Owens, J. S., Pelham, W. E., \& Kipp, H. (2001). Academic task persistence of normally achieving ADHD and control boys: Self-evaluations, and attributions. Journal of Consulting and Clinical Psychology, 69(2), 271. doi:10.1037/1064-1297.9.4.425

Hoza, B., Waschbusch, D. A., Pelham, W. E., Molina, B. S. G., \& Milich, R. (2000). Attention-deficit/hyperactivity disordered and control boys' responses to social success and failure. Child Development, 71, 432446. doi:10.1111/1467-8624.00155

Hu, L., \& Bentler, P. M. (1999). Cutoff criteria for fit indexes in covariance structure analysis: Conventional criteria versus new alternatives. Structural Equation Modeling, 6, 1-55. doi:10.1080/10705519909540118

Humphreys, K. L., \& Lee, S. S. (2011). Risk taking and sensitivity to punishment in children with ADHD, ODD, ADHD + ODD, and controls. Journal of Psychopathology and Behavioral Assessment, 33, 299307. doi:10.1007/s10862-011-9237-6

Humphreys, K. L., Mehta, N., \& Lee, S. S. (2012). Association of parental ADHD and depression with externalizing and internalizing dimensions of child psychopathology. Journal of Attention Disorders, 16, 267-275. doi: $10.1177 / 1087054710387264$

Johnston, C., \& Mash, E. J. (2001). Families of children with attentiondeficit/hyperactivity disorder: Review and recommendations for future research. Clinical Child and Family Psychology Review, 4, 183-207. doi:10.1023/A:1017592030434

Katz, S. J., Conway, C. C., Hammen, C. L., Brennan, P. A., \& Najman, J. M. (2011). Childhood social withdrawal, interpersonal impairment, and young adult depression: A mediational model. Journal of Abnormal Child Psychology, 39, 1227-1238. doi:10.1007/s10802-011-9537-z
Katz, S. J., Hammen, C. L., \& Brennan, P. A. (2013). Maternal depression and the intergenerational transmission of relational impairment. Journal of Family Psychology, 27, 86-95. doi:10.1037/a0031411

Kaufman, J., Martin, A., King, R. A., \& Charney, D. (2001). Are child-, adolescent-, and adult-onset depression one and the same disorder? Biological Psychiatry, 49, 980-1001. doi:10.1016/S00063223(01)01127-1

Keeping, J. D., Najman, J. M., Morrison, J., Western, J. S., Andersen, M. J., \& Williams, G. M. (1989). A prospective longitudinal study of social, psychological, and obstetrical factors in pregnancy: Response rates and demographic characteristics of the 8,556 respondents. British Journal of Obstetrics and Gynaecology, 96, 289-297. doi:10.1111/j .1471-0528.1989.tb02388.x

Kelloway, E. K. (1998). Using LISREL for structural equation modeling: A researcher's guide. Thousand Oaks, CA: Sage.

Kessler, R. C., Birnbaum, H. G., Shahly, V., Bromet, E., Hwang, I., McLaughlin, K. A., . . . Stein, D. J. (2010). Age differences in the prevalence and co-morbidity of $D S M-I V$ major depressive episodes: Results from the WHO World Mental Health Survey Initiative. Depression and Anxiety, 27, 351-364. doi:10.1002/da.20634

Lahey, B. B., Applegate, B., McBurnett, K., \& Biederman, J. (1994). $D M S-I V$ field trials for attention deficit hyperactivity disorder in children and adolescents. The American Journal of Psychiatry, 151, 16731685.

Lahey, B. B., Miller, T. L., Gordon, R. A., \& Riley, A. W. (1999). Developmental epidemiology of the disruptive behavior disorders. In H. C. Quay \& A. E. Hogan (Eds.), Handbook of disruptive behavior disorders (pp. 23-48). New York, NY: Kluwer Academic/Plenum Press doi:10.1007/978-1-4615-4881-2_2

Leadbeater, B. J., Blatt, S. J., \& Quinlan, D. M. (1995). Gender-linked vulnerabilities to depressive symptoms, stress, and problem behaviors in adolescents. Journal of Research on Adolescence, 5, 1-29. doi:10.1207/ s15327795jra0501_1

Lee, S. S., \& Hinshaw, S. P. (2006). Predictors of adolescent functioning in girls with attention deficit hyperactivity disorder (ADHD): The role of childhood ADHD, conduct problems, and peer status. Journal of Clinical Child and Adolescent Psychology, 35, 356-368. doi:10.1207/ s15374424jccp3503_2

Lifford, K. J., Harold, G. T., \& Thapar, A. (2008). Parent-child relationships and ADHD symptoms: A longitudinal analysis. Journal of Abnormal Child Psychology, 36, 285-296. doi:10.1007/s10802-007-9177-5

Lifford, K. J., Harold, G. T., \& Thapar, A. (2009). Parent-child hostility and child ADHD symptoms: A genetically sensitive and longitudinal analysis. Journal of Child Psychology and Psychiatry, 50, 1468-1476. doi:10.1111/j.1469-7610.2009.02107.x

McCarty, C. A., Mason, W. A., Kosterman, R., Hawkins, J. D., Lengua, L. J., \& McCauley, E. (2008). Adolescent school failure predicts later depression among girls. Journal of Adolescent Health, 43, 180-187. doi:10.1016/j.jadohealth.2008.01.023

McLeod, B. D., Weisz, J. R., \& Wood, J. L. (2007). Examining the association between parenting and childhood depression: A metaanalysis. Clinical Psychology Review, 27, 986-1003. doi:10.1016/j.cpr .2007.03.001

McQuade, J. D., Hoza, B., Murray-Close, D., Waschbusch, D. A., \& Owens, J. S. (2011). Changes in self-perceptions in children with ADHD: A longitudinal study of depressive symptoms and attributional style. Behavior Therapy, 42, 170-182. doi:10.1016/j.beth.2010.05.003

Muthén, L. K., \& Muthén, B. O. (1998-2010). Mplus user's guide (6th ed.). Los Angeles, CA: Author.

Najman, J. M., Behrens, B. C., Andersen, M., Bor, W., O'Callaghan, M., \& Williams, G. M. (1997). Impact of family type and family quality on child behavior problems: A longitudinal study. Journal of the American Academy of Child \& Adolescent Psychiatry, 36, 1357-1365. doi 10.1097/00004583-199710000-00017 
Najman, J. M., Williams, G. M., Nikles, J., Spence, S., Bor, W., O'Callaghan, M., . . . Shuttlewood, G. J. (2001). Bias influencing maternal reports of child behaviour and emotional state. Social Psychiatry and Psychiatric Epidemiology, 36, 186-194. doi:10.1007/ s001270170062

Ostrander, R., Crystal, D. S., \& August, G. (2006). Attention deficithyperactivity disorder, depression, and self- and other-assessments of social competence: A developmental study. Journal of Abnormal Child Psychology, 34, 772-786. doi:10.1007/s10802-006-9051-x

Ostrander, R., \& Herman, K. C. (2006). Potential cognitive, parenting, and developmental mediators of the relationship between ADHD and depression. Journal of Consulting and Clinical Psychology, 74, 89-98. doi:10.1037/0022-006X.74.1.89

Owens, J., \& Hoza, B. (2003). Diagnostic utility of DSM-IV-TR symptoms in the prediction of DSM-IV-TR ADHD subtypes and ODD. Journal of Attention Disorders, 7(1), 11-27. doi:10.1177/108705470300700102

Owens, J. S., Goldfine, M. E., Evangelista, N. M., Hoza, B., \& Kaiser, N. M. (2007). A critical review of self-perceptions and the positive illusory bias in children with ADHD. Clinical Child and Family Psychology Review, 10, 335-351. doi:10.1007/s10567-007-0027-3

Panak, W. F., \& Garber, J. (1992). Role of aggression, rejection, and attributions in the prediction of depression in children. Development and Psychopathology, 4, 145-165. doi:10.1017/S0954579400005617

Patterson, G. R., DeBaryshe, B. D., \& Ramsey, E. (1989). A developmental perspective on antisocial behavior. American Psychologist, 44, 329335. doi:10.1037/0003-066X.44.2.329

Patterson, G. R., \& Stoolmiller, M. (1991). Replications of a dual failure model for boys' depressed mood. Journal of Consulting and Clinical Psychology, 59, 491-498. doi:10.1037/0022-006X.59.4.491

Pelham, W. E., Jr., Fabiano, G. A., \& Massetti, G. M. (2005). Evidencebased assessment of attention deficit hyperactivity disorder in children and adolescents. Journal of Clinical Child and Adolescent Psychology, 34, 449-476. doi:10.1207/s15374424jccp3403_5

Pelham, W. E., Jr., Gnagy, E. M., Greenslade, K. E., \& Milich, R. (1992). Teacher ratings of $D S M-I I I-R$ symptoms for the disruptive behavior disorders. Journal of the American Academy of Child \& Adolescent Psychiatry, 31, 210-218. doi:10.1097/00004583-199203000-00006

Piccinelli, M., \& Wilkinson, G. (2000). Gender differences in depression: Critical review. The British Journal of Psychiatry, 177, 486-492. doi: 10.1192/bjp.177.6.486

Rao, U., Hammen, C., \& Daley, S. E. (1999). Continuity of depression during the transition to adulthood: A 5-year longitudinal study of young women. Journal of the American Academy of Child \& Adolescent Psychiatry, 38, 908-915. doi:10.1097/00004583-199907000-00022

Robins, L. N. (1986). The consequences of conduct disorder in girls. In D. Olweus, J. Block, \& M. Radke-Yarrow (Eds.), Development of antisocial and prosocial behavior: Research, theories, and issues (pp. 385409). New York: Academic.

Rudolph, K. D., Hammen, C., Burge, D., Lindberg, N., Herzberg, D., \& Daley, S. E. (2000). Toward an interpersonal life-stress model of depression: The developmental context of stress generation. Development and Psychopathology, 12, 215-234. doi:10.1017/S0954579400002066
Safford, S. M., Alloy, L. B., \& Pieracci, A. (2007). A comparison of two measures of parental behavior. Journal of Child and Family Studies, 16, 375-384. doi:10.1007/s10826-006-9092-3

Schludermann, S., \& Schludermann, E. (1988), Shortened Child Report of Parent Behavior Inventory (CRPBI-30): Schludermann revision. Unpublished manuscript, University of Manitoba, Winnipeg, Canada.

Seroczynski, A. D., Cole, D. A., \& Maxwell, S. E. (1997). Cumulative and compensatory effects of competence and incompetence on depressive symptoms in children. Journal of Abnormal Psychology, 106, 586-597. doi:10.1037/0021-843X.106.4.586

Seymour, K. E., Chronis-Tuscano, A., Halldorsdottir, T., Stupica, B. Owens, K., \& Sacks, T. (2012). Emotion regulation mediates the relationship between ADHD and depressive symptoms in youth. Journal of Abnormal Child Psychology, 40, 595-606. doi:10.1007/s10802-0119593-4

Shaffer, D., Fisher, P., Lucas, C. P., Dulcan, M. K., \& Schwab-Stone, M. E. (2000). NIMH Diagnostic Interview Schedule for Children Version IV (NIMH DISC-IV): Description, differences from previous versions, and reliability of some common diagnoses. Journal of the American Academy of Child \& Adolescent Psychiatry, 39, 28-38. doi:10.1097/ 00004583-200001000-00014

Shemmassian, S. K., \& Lee, S. S. (2012). Comparing four methods of integrating parent and teacher symptom ratings of attention-deficit/ hyperactivity disorder (ADHD). Journal of Psychopathology and Behavioral Assessment, 34, 1-10. doi:10.1007/s10862-011-9262-5

Smart, D., Sanson, A., \& Prior, M. (1996). Connections between reading disability and behavior problems: Testing temporal and causal hypotheses. Journal of Abnormal Child Psychology, 24, 363-383. doi:10.1007/ BF01441636

Stice, E., Ragan, J., \& Randall, P. (2004). Prospective relations between social support and depression: Differential direction of effects for parent and peer support? Journal of Abnormal Psychology, 113, 155-159. doi:10.1037/0021-843X.113.1.155

Szatmari, P., Offord, D. R., \& Boyle, M. H. (1989). Ontario Child Health Study: Prevalence of attention deficit disorder with hyperactivity. Journal of Child Psychology and Psychiatry and Allied Disciplines, 30 219-230. doi:10.1111/j.1469-7610.1989.tb00236.x

Webster-Stratton, C. (1992). The incredible years. Seattle, WA: The Incredible Years. Retrieved from http://www.incredibleyears.com

Webster-Stratton, C., \& Herman, K. C. (2008). The impact of parent behavior-management training on child depressive symptoms. Journal of Counseling Psychology, 55, 473-484. doi:10.1037/a0013664

Wechsler, D. L. (2002). Wechsler Individual Achievement Test_II. San Antonio, TX: Psychological Corporation.

Willcutt, E. G., Nigg, J. T., Pennington, B. F., Solanto, M. V., Rohde, L. A., Tannock, R., . . . Lahey, B. B. (2012). Validity of $D S M-I V$ attention deficit/hyperactivity disorder symptom dimensions and subtypes. Journal of Abnormal Psychology, 121, 991-1010. doi:10.1037/ a0027347

Received August 16, 2012

Revision received May 28, 2013

Accepted May 28, 2013 